\title{
A vignette model for distributed teaching and learning
}

\author{
Marcel Chaloupka and Tony Koppi \\ Centre for Teaching and Learning, University of Sydney
}

Computer software and telecommunication technologies are being assimilated into the education sector. At a slower pace, educational methodologies have been evolving and gradually adopted by educators. The widespread and rapid assimilation of technology may be outstripping the uptake of better pedagogical strategies. Non-pedagogical development of content could lead to the development of legacy systems that constrain future developments. Problems have arisen with computer-based learning (CBL) materials, such as the lack of uptake of monolithic programmes that cannot be easily changed to keep pace with natural progress or the different requirements of different teachers and institutions. Also, hypertext/hypermedia learning environments have limitations in that following predefined paths is no more interactive than page turning. These considerations require a flexible and dynamic approach for the benefit of both the teacher and student. Courses may be constructed from vignettes to meet a desired purpose and to avoid the problems of adoption for the reasons that programmes cannot easily be changed or are not designed to meet particular needs. Vignettes are small, first-principle, first-person, heuristic activities (which are mimetic) from which courses can be constructed. Vignettes use an objectorientated approach to the development of computer-based learning materials. Vignettes are objects that can be manipulated via a property sheet, which enables changing the object's inherent character or behaviour. A vignette object can interact with other vignette objects to create more complex educational interactions or models. The vignette approach leads to a development concept that is horizontally distributed across disciplines rather than vertically limited to single subjects.

\section{Introduction}

The notion of convergence of disparate technologies has become popular with governments, computing and business sectors in the 1990s; but how has the convergence been implemented in the educational sector? One evident area of convergence in education has been the use of the Internet. But according to Gosper et al (1996), the most likely strategies for implementation are to use the Internet as a repository of reference, lecture materials and the presentation of the lectures. This could imply that the full potential of distributed learning through convergence might never be achieved. How can we implement good learning strategies following sound educational methodologies today, while not producing legacy systems or piecemeal content that could constrain future developments? In making it possible for distributed learning to occur, there are best-practice considerations applicable to most educational environments. 
This paper considers the issues associated with distributed learning in the context of the recent history of computer-aided learning developments. Particular problems have arisen with Computer-Based Learning (CBL) materials, such as the lack of uptake of monolithic programmes that cannot easily be changed to keep pace with natural progress or the different requirements of different institutions. The shift in recent emphasis towards the Internet has not resolved these problems which may be more pertinent because of the potentially wider field of ever-more discerning users. A solution to monolithic developments is in the use of object-oriented vignettes that can be used to assemble learning materials to suit individual learners (including prior learning and professional development considerations) as well as individual teaching preferences. The issues associated with hypertext/hypermedia have increased in importance with increased use of the Internet. The concept of mimetics, first-person learning interfaces (as opposed to navigation structures) and interactivity are also no less relevant when designing learning programmes for distribution over the Internet.

\section{Distributed learning}

Radio, television and mailing of documents and educational software of many flavours have been the main delivery mechanisms that have driven the implementation of distance learning. The Internet is fast becoming a seductive delivery medium. But is distance learning, or learning for that matter, about the ability to deliver learning material rapidly to a client? The methodologies that have been implemented in distance learning imply a oneway flow of information to the client, given that the client may phone, email or mail assignments to the course facilitator. This one-way flow of educational material does not seem to take advantage of the telecommunications revolution that has been brought about by convergent technologies. It seems that educational practice often is incongruent with notional educational theory such as collaboration, peer-to-peer learning, mentoring, apprenticeship or heuristic models of learning.

If what Kveton and Vesela (1996) say ('Teachers will become advisors, managers and facilitators of learning rather than providers of information') has any relevance, we need to look at different ways of developing and implementing distance education. Distributed learning addresses the issues of the teachers being advisers, managers and facilitators, and thus provides a means by which an educational or training facility can implement a full two-way educational experience in a divergent market where the location and distribution of the teaching resources and participants (students, teachers, etc.) are irrelevant.

The model for distributed learning described here takes influences from traditional methodologies of teaching and learning, but before discussion of the model we need to look at the reasons that have led to the model, and why some, perhaps obvious, options have been avoided.

\section{Hypermedia and learner control}

Part of the notion of distributed learning is that students take control and responsibility for their learning rather than being passive recipients of information. To this end, in a digital context, hypertext/hypermedia environments have been touted as eliciting learner control (Chung and Reigeluth, 1992) and providing a dynamic, systematic relationship between the learning environment and the learner (Locatis et al, 1989; Wilson and Jonasson 1989). 
Shin et al (1994) state: 'In a Hypertext environment, use of learner control is inevitable because hypermedia creates non-sequential, dynamic, and multiple structures of information that allow the learners with different interests to navigate multiple pathways through the information'. But how can a collection of static pages on a computer, with predefined pathways and schema, automatically and inevitably allow learner control, when the learner is actually involved in the consumption of predefined content through a structure that is no more dynamic or interactive than turning pages in a book? Hypertext is passive by nature: the learner may fail to engage with the materials in ways that result in effective learning (McKnight et al, 1993). Hypertext/hypermedia, as the primacy of the learning experience, show that little or no thought has been given to the cognitive aspects of interactivity (Laurillard, 1993), leaving the student to become a passive agent to a narrative (Alessi and Trollip 1991; Laurel 1991).

Thus to transfer a book or learning material in its current form into hypertext/hypermedia to be the primacy of the learning experience allows the user only to follow predefined pathways and does not take full advantage of the technological platform; it is merely repackaging (Diller, 1995). Borsook and Higginbotham-Wheat (1991) indicate that software that provides only backward and forward movement in the presentation of information simply talks or communicates at, not with, the learner in a co-responsive manner. The primacy of the learning experience should be more than having access to or looking at information. Students need to be enabled to examine, perceive, interpret and experience information thereby converting information into knowledge. Interactive media provide these opportunities only when users can visualize and understand complex relationships in ways that are not possible in other media.

\section{Monolithic computer-based learning}

The development of CBL has historically been the development of monolithic learning applications, that is, those designed to be self-contained, self-standing and containing large amounts of information. Many of these CBL applications are based on a tutorial-type method of content delivery. They may include features such as notepads, calculators and reference materials, perhaps to support some activities. In addition, hypertext/hypermedia is a common feature.

The primacy of locus of control is commonly that of the interface. The notion of learnercontrol via the navigational interface is an explicit action of the interface. In other words, the student has to learn the interface before learning the information within the application. It would be a more direct relevant experience with the information if learning and understanding the interface were part of a process of interacting directly with the information in a first-person heuristic.

Other limitations to the development of monolithic CBL include the cost of development, time restrictions of academics contributing to the project, changes after completion, and issues of inter-disciplinary replication between disparate developments.

\section{Changing the content after compilation}

In the academic world, content (as information) will always need to be modified, appended and edited. Also, different experts see the value of content differently: not everyone wants 
to teach a subject in the same way. Information is evolutionary, and sometimes capricious, so developing monolithic CBL for content delivery is perhaps inappropriate. It may help if we could change the primacy of the learning experience to heuristic activities (Koppi and Chaloupka, 1997) that encourage the student to seek meaning by accessing a variety of media and informational resources because of a need to do so. The outcome of this could be for the student to have an experience with information (Laurel, 1991), as opposed to the student merely being presented with information for learning.

Basic heuristic activities do not need to be changed because of their content transparency, but should be contextually truthful to a first principle concept or process; for example, performing a pH test is based on the same concept whatever the particular disciplinary perspective. In this scenario, content, information and the dynamics of information can be thought of in term of libraries, that is, a collection of catalogued reference and resource materials as a support to the activities.

Considering content as reference material that can be accessed physically or electronically, from centralized locations, enables changes to be made by academics and students as well as for ongoing professional development.

\section{We don't teach it that way}

It is unlikely that the content within a CBL is not appropriate for the course, as one would expect that the content is an abstraction from one or more experts. Perhaps the 'we don't teach it that way' syndrome results from the content not being accessible in a way in which the subject is taught. A course is constructed to utilize a variety of sources and activities, for example reading lists, photocopies of articles and chapters from books, dry labs, fieldwork, assignments, discussions and tutorials. The range of experiences and resources between academics will inherently be different, but there will also be core similarities.

Each of these resources and experiences on a micro level could be heuristic and learnercentred in nature. The motivation of the teacher should not be to present or give access to resources as the primary learning experience, but to give an authentic activity as the primacy of the learning experience which drives the need to seek understanding.

Historically, CBL has tended to offer a prescriptive approach to the teaching processes, and not to offer a range of teaching heuristics that are usable by individual academics from their own teaching perspectives and needs. Developers of CBL concentrate on the notion of learner-centric $C B L$, but at the same time tend to be didactic towards teaching the teaching process: an all-or-nothing approach. It would seem as if the two notions of student- and teacher-centric approaches are incompatible.

\section{Vignettes}

A vignette approach may be a solution to the 'we don't teach it that way' issue. This requires changing the perspective of the learning experience from content delivery (in other words, narratives in the third person interlaced with questions of comprehension) to firstperson heuristics where the learner is engaged in hypothesis testing and problem-solving in the first person. This is aimed at encouraging the learner to seek the meaning of the activity by purposefully accessing resource or content materials. 
Vignettes can be defined as small, first-principle, first-person, heuristic activities (components), from which courses are constructed. Vignettes are transparent to content but are supported by reference materials that are accessed electronically, form centralized locations, as separate materials but integrated into the learning environment. Thereby, the supportive resource materials can be added to by a teacher, and edited and contributed to by colleagues on an ongoing basis, thus avoiding the "can I change the content after the program has been completed?' issue.

Separating the vignette activities from the content allows the vignettes to be content-free, but in another sense the vignette activities are content-rich in the relationship of the object behaviour through a contextual interface (rather than a navigation interface). The vignettes are then supported by the centralized reference materials which are stored in an appropriate domain such a digital library which can be accessed via networked technology and can be changed without the need to modify the vignettes.

A vignette object has inherent behaviour which is not changed by content. For example, a test tube has behaviours: it is made from glass; it can make a clinking sound when struck; it is clear; it cannot stand unless supported; it can be broken; things can be put in it. If we were to write a vignette about a test tube, we would want to put these inherent behaviours into it. But not all the behaviours relevant to a vignette object are relevant to all courses that might use test tubes. This problem can be addressed by allowing the properties of the vignette object to be changed, by turning on and off the available object properties of the vignette object, thus modifying the vignette behaviour to suit the purposes of the user. For instance, the test tube could contain a range of aqueous chemicals but in the course that we are constructing we want only a range of ionic compounds that are soluble in water to be visible. So, by accessing the test-tube property sheet, we could turn off the chemicals we do not want the students to see, while leaving the ionic compounds that are soluble in water and that suit the course agenda. Now we have a test-tube vignette with modifiable object behaviour. Part of the test-tube object behaviour is that it can be filled with chemicals. When the vignette is activated we see a test tube; if the test tube is clicked on, a list of available chemicals is shown. Clicking on one of the items in the list fills the test tube with a chosen item. By itself this is of no use unless we have other vignette objects with which our test-tube vignette object can interact. So, in the course that may be constructed, another test-tube vignette object (a clone of the first) can be activated, together with a beaker vignette object to enable mixing of the chemicals. Now we have two test tube objects with, say, aqueous ionic compounds in them, and an empty beaker. The test tubes empty into the beaker; this is what we call the primacy of action. Just like vignette objects have object behaviour, groups of objects can have primacy of action like hammer and nail, stapler and paper, test tubes and beakers. There is an inherent behaviour between objects; as each object has its own unique behaviour, groups of vignette objects have group behaviour or action.

This group behaviour is hierarchical; for instance, the nail reacts to the hammer. The hammer is the dominant object, the action goes from the hammer to the nail. If we introduced wood to the group, the action would transfer from the hammer to the nail to the wood. But let us say that instead of introducing wood we introduced steel to the group. In this scenario we have two objects that are dominant over the nail whose object behaviour is hierarchically higher than that of the nail. The primacy of action would say that the hammer hits the nail and the nail bends on steel, as both the hammer and the steel 
can change the behaviour or characteristic of the nail. The beaker like the hammer, nail and steel reacts to the primacy of action of the two full test tubes, which fill the beaker, and a reaction of the two chemicals occurs within the beaker.

But vignettes alone do not make an educational experience. Vignettes are but a part of a broader and more comprehensive approach to the delivery of CBL that reflects a teacher heuristic. Imagine for a moment that you want to make a course based on these ideas. You start by launching your Computer Management Learning (CML) package and click on Search. You type in the content area of the course you wish to create, let us say Soil Science. The search pulls up a list of teaching resources and materials that have been created all over the world that could be used in teaching Soil Science. Some of these resources and materials could be Web discussions, vignettes, reference materials, assessments, teaching guides as well as other teacher resources. You click on a vignette and it launches. Among other things, a core component of your course is $\mathrm{pH}$. You click on $\mathrm{pH}$ and a $\mathrm{pH}$ vignette launches. The $\mathrm{pH}$ vignette does not have a Soil Science look or feel; it has a chemistry feel, but because vignettes are based on the notion of Object-Oriented Programming, they have property sheets. You pull up the property sheet and it allows you to change the in-built characteristics of the vignette. For Soil Science, you want to use a tile in which samples can be placed. The sample type will be soil, so you change the soil properties to suit the soil types you want the students to examine. The vignette now fits your requirements as a component, so you add it to the course you are constructing. Now you want some supportive resources, and you add some available reference materials to the course. You also add some peer-to-peer learning as a threaded discussion, as well as some assessment components. After you have pooled the educational materials to be used in the course, you choose the students that will have access to these materials. You add course objectives and a problem-based scenario. While you are making the choices of the core components of your course and its members, the CML is constructing a Web page. This Web page is accessible only to the students that have been made members of this course. When the students log on, they will see the course outline, course objective, problem-based scenario, and buttons that launch the vignettes, reference materials, discussion areas, etc.

This vignette approach to development allows academics to construct courses in much the same way that is traditionally acceptable. It also allows the vignette to be used in a number of situations and applied across disciplines. Thus the program development is a horizontal process as opposed to a vertical development process which is discipline-based as represented by the monolithic development approach. Because vignettes are single-issue first-principle activities that can be readily modified, they can be shared between disciplines. For instance, $\mathrm{pH}$ is taught in a variety of disciplines including medicine, biology, agriculture and chemistry. A pH vignette could be developed and used in each discipline by adopting an object-oriented approach to the programming of the application. The vignette object would contain all the contextual information appropriate to the allied disciplines. The $\mathrm{pH}$ object is then externally manipulated through its associated property sheet. This would enable the course facilitator to manipulate the object's behaviour to that of the discipline's perspective. Different objects can be linked to form larger learning activities of greater complexity or visualization.

Other advantages in a vignette approach to CBL development are: it does not engender replication of similar materials across diverse disciplines; vignettes are cheap and fast to 
develop; vignettes have a longer shelf-life than monolithic CBL which has the content embedded within the application, and which is inaccessible in a non-linear basis or on a just-in-time basis, as well as being unchangeable without reprogramming.

This process of vignette development should allow greater penetration and uptake of the technology by being sensitive to the machinations and needs of academics in a traditionally acceptable manner. A vignette-constructed programme should allow the academic to access and use the courseware content in a way that reflects the needs of the academic to facilitate and manage their course.

For the vignette object to engage the student in a first-person activity, it is important to consider what is meant by a heuristic activity, and this is considered in the next section.

\section{Mimetics}

Mimetics is concerned with mimicking the real world to provide experiences similar to reallife where the appropriate set of external conditions exists (Koppi and Chaloupka, 1996). Computer games and training simulations use mimetics extensively to give life-like experiences. Volk (1996) says:

Games themselves are stills based on one or more interactive experiences of exploration, resource allocation, action and strategy. Creative authors take advantage of increased technological power primarily to heighten the emotional impact of their creations. In nearly 20 years, most of the evolution has been in interface design. Which brings us to the central point: technology is the palette that interactive designers use to create experiences for other people. Technology is not a goal. The goal is to create a title that delivers the interactive experience the designer wants.

Presenting information in dramatic from, as an active first-person encounter, provides a means for comprehending and therefore is a learning activity to encounter information itself (Laurel, 1991). So it would seem that activities are important for engaging the student in a learning activity where the action and activity evoke thought.

Mimetic worlds provide a realistic context for exploration and heuristic activities, which enable the learner to interact and model an environment in the first person. The interactivity provided in these environments can enable learners to construct schemas and test hypotheses against the environment, and see the results of their actions, thus gaining experience, in relatively short time periods. Such environments or work areas reflect the processes or schema where the behaviour of the objects or environment behaves as expected. As well as giving learner-centric locus of control, this is a key factor in the sustained stimulation and motivation of the learner (Alessi and Trollip, 1991). The environment must be credible to allow a catharsis to occur while permitting a sustained engagement of the imagination (Laurel, 1991) and decision-making process. The challenge in developing this type of learning environment is to facilitate imaginative immersion that enables experiences, learner control and reflective reasoning (Leyland, 1996).

\section{Conclusion}

Courses can be constructed from a vignette model that takes into account the student and teacher needs. Vignettes offer a solution to the problems of, course adoption and 
modification. It is also important to see the learning activities as vignettes where the interaction is not cognitively separate from the learning activity. The main reason for this is so that the learning approach of discovery and self-motivation enables the learner to seek understanding and to be able to construct new knowledge based on prior knowledge.

Learning materials cannot be functionally isolated from an overall teaching and learning strategy. Learning materials themselves cannot be the sole teaching and learning strategy. Each is a small piece in the overall strategy of deliverable learning activities, reference, support, and assessment in an enterprise-wide solution. It is also important to acknowledge that a teacher's teaching locus of control is as important as learner heuristics in the design, development and deployment of CBL.

To enable curiosity, motivation and self-empowerment, it is necessary to provide a heuristic learning environment that is supported by resources and reference materials rather than this content being the primary learning material. The qualities of a heuristic learning environment include the capacity of the program to be used as a reflective thinking tool, frequency of interaction, range of choices, and significance, that is to say how much the choices really affect the outcomes (Laurel 1986a and b). The purpose is to making learning activities an experience with information where content delivery is not the primacy of the learning experience but the manipulation of an environment so as to have an experience with the information or concepts. Curiosity, empowerment and self-direction are interdependent, and should not be seen as extraneous to the learning environment as a laminate or facade bonded onto content.

\section{References}

Alessi, S. M. and Trollip, S. R. (1991), Computer-Based Instruction Methods and Development, New Jersey: Prentice Hall.

Borsook, T. K. and Higgenbothom-Wheat, N. (1991), 'Interactivity: what is it and what can it do for computer based instruction?', Educational Technology, 32 (10), 11-17.

Diller, B. (1995), 'Don't repackage - redefine!', http://www.Hotwired.com/wired/3.02/ departments/electroshere/diller.html

Gosper, M., Andrews, J., Hesketh, B. and Sabaz, M. (1996), 'Electronic communication in university teaching: expectations and implication over the next five years' in Christie, A., James, P. and Vaughan, B. (eds), Proceedings of the 13th Annual Conference of the Australian Society for Computers in Learning in Tertiary Education (ASCILITE), Adelaide: The University of South Australia, 375-80.

Koppi, A. J. and Chaloupka, M. J. (1996), The Soil Investigation Kit: A Mimetic Environment for Introductory Soil Science (software), University of Sydney, http://nettl.usyd. edu.au/sik

Koppi, A. and Chaloupka, M. (1997), 'Heuristic contextual action works best', Proceedings of the 14th Annual Conference of the Australian Society for Computers in Learning in Tertiary Education (ASCILITE), Perth: Curtin University, (in press).

Kveton, K. and Vesela, E. (1996), 'Distant Education and the Internet', 96 UNESCO International Centre for Scientific Computing, http//www.crut.cz/ascii/cc/SEFI/Vienna96.html 
Laurel, B. (1986a), 'Toward the Design of a Computer-Based Interactive Fantasy System', Ph.D dissertation, Ohio: The Ohio State University.

Laurel, B. (1986b), 'Interface as mimesis' in Norman, D. A. and Draper, S. (eds), UserCentered System Design: New Perspectives on Human-Computer Interaction, Hillsdale NJ: Laurence Erlbaum.

Laurel, B. (1991), Computers as Theatre, Reading, MA: Addison Wesley.

Laurillard, D. (1993), Rethinking University Teaching, London: Routledge.

Leyland, B. (1996), 'How can computer games offer deep learning and still be fun? A progress report on a game in development' in Christie, A., James, P. and Vaughan, B. (eds), Proceedings of the 13th Annual Conference of the Australian Society for Computers in Learning in Tertiary Education (ASCILITE), Adelaide: The University of South Australia, 375-80.

Locatis, C., Letourneau, G., and Banvard,. R. (1989), 'Hypermedia and instruction', Educational Technology Research and Development, 37 (4), 65-77.

McKnight, C., Dillon, A. and Richardson, J. (1993), Hypertext: A Psychological Perspective, Sydney: Ellis Horwood.

Shin, E. C., Schallert, D. L. and Savenye, W. C. (1994), 'Effects of learner control, advisement, and prior knowledge on young students' learning in a hypertext environment', Educational Technology Research and Development, 42 (1), 33-46.

Wilson, F. and Jonasson, D. (1989), 'Hypertext and instruction design: some preliminary guidelines', Performance Improvement Quarterly, 2 (3), 34-49.

Volk, W. (1996), 'Why can't Johnny Ship?', Interactivity, 2 (4), 34. 